\title{
First considerations on post processing kinematic GNSS data during a geophysical oceanographic cruise
}

\author{
Valerio Baiocchi ${ }^{1}$, Alessandro Bosman ${ }^{2}$, Gino Dardanelli ${ }^{3}$, Francesca Giannone ${ }^{4}$ \\ ${ }^{1}$ Dipartimento Ingegneria Civile, Edile ed Ambientale(DICEA), Sapienza Università di Roma, Via Eudossiana 18, I00184, Italy \\ ${ }^{2}$ Istituto di Geologia Ambientale e Geoigegneria, Consiglio Nazionale delle Ricerche (CNR- IGAG), Rome, Italy \\ ${ }^{3}$ Department of Civil, Environmental, Aerospace, Materials Engineering (DICAM), University of Palermo, Italy \\ ${ }^{4}$ Department of Engineering, Niccolò Cusano University, Via Don Carlo Gnocchi 3, Rome, I 00166, Italy
}

\section{ABSTRACT}

Differential GNSS positioning on vessels is of considerable interest in various fields of application as navigation aids, precision positioning for geophysical surveys or sampling purposes especially when high resolution bathymetric surveys are conducted. However ship positioning must be considered a kinematic survey with all the associated problems. The possibility of using high-precision differential GNSS receivers in navigation is of increasing interest, also due to the very recent availability of low-cost differential receivers that may soon replace classic navigation ones based on the less accurate point positioning technique. The availability of greater plano-altimetric accuracy, however, requires an increasingly better understanding of planimetric and altimetric reference systems. In particular, the results allow preliminary considerations on the congruence between terrestrial reference systems (which the GNSS survey can easily refer to) and marine reference systems (connected to National Tidegauge Network). In spite of the fluctuations due to the physiological continuous variation of the ship's attitude, GNSS plot faithfully followed the trend of the tidal variations and highlighted the shifts between GNSS plot and the tide gauges due to the different materialization of the relative reference systems.

Section: RESEARCH PAPER

Keywords: GNSS; bathymetry survey; RTK-Lib; geoid; Tyrrhenian Sea

Citation: Valerio Baiocchi, Alessandro Bosman, Gino Dardanelli, Francesca Giannone, First considerations on post processing kinematic GNSS data during a geophysical oceanographic cruise, Acta IMEKO, vol. 10, no. 4, article 6, December 2021, identifier: IMEKO-ACTA-10 (2021)-04-06

Section Editor: Silvio Del Pizzo, University of Naples 'Parhenope', Italy

Received June 1, 2021; In final form December 6, 2021; Published December 2021

Copyright: This is an open-access article distributed under the terms of the Creative Commons Attribution 3.0 License, which permits unrestricted use, distribution, and reproduction in any medium, provided the original author and source are credited.

Funding: This work was supported by Italian National Research Council (CNR)

Corresponding author: Valerio Baiocchi, e-mail: valerio.baiocchi@uniroma1.it

\section{INTRODUCTION}

The problem of calculating the connection between on-shore and off-shore heights is still very open and debated. In fact, even though they are all heights, they are referred to reference systems with non-equivalent definitions, so conceptually and numerically very different, and this often makes the connection between the two types of heights complex [1]. The ground altimetric reference system is generally based on the definition of a specific equipotential surface of the gravitational field, identified by the mean level of a reference tide gauge. This method has been used in Italy both historically [2] and currently [3] and various national terrestrial altimetric systems have been defined, for this reason the possibility of unifying them at a regional [4] and global level [5] is currently subject of research. GNSS systems have made it possible for the first time to obtain highly accurate plano- altimetric measurements (and therefore also elevation measurements) both on land and at sea; however, these measurements do not refer to a physical reality but to a mathematical surface, the ellipsoid of rotation. On land, ellipsoid elevations are transformed into orthometric elevations using local geoid models [6], which are generally more accurate, or global models, which are generally less accurate [7]. The problem of elevations at sea is even more complex because the sea surface is not an equipotential surface, which is "... characterized by uniform temperature and density and free of perturbations related to currents, winds and tides." [8] Unfortunately, these are ideal conditions that are never found in nature, and for this reason the materialisation of altimetric reference systems at sea is profoundly different from terrestrial altimetric reference systems [9]. It is important to underline that the interest in this case is mainly in seafloor depth in order to construct high resolution digital elevation model (DEMs) for seafloor, habitat 
mapping and bathymetric cartographies which are mainly used for navigational, safety and scientific bathymetric surveys [10][12]. The elevations at sea are often referred to a conventional local zero identified with a local tide gauge, conventionally the tide gauge's "zero" has no connection with the "zero" of the national altimetric system; bathymetries are referred to the tide gauges reference system for prudential reasons related to navigation and nautical charts [9]. Therefore, there is no congruence between the zero of the tide gauges and the national altimetric system, not even between the various tide gauges at a given time. It must also be taken into account that the connection between the national altimetric system and the elevations on the islands cannot be made by precision geometric levelling but it is often made by trigonometric levelling or GNSS levelling corrected later with the same geoid models [13]. The interest in the correct relationship between terrestrial and tidal altimetry systems is constantly increasing both for the growing interest in the automatic extraction of coastlines [14]-[16] and for the very recent availability of low cost GNSS receivers that can acquire in differential mode, allowing centimetric and potentially also millimetric [17] planimetric accuracy even at sea.

In this paper, the first results of a Post Processing Kinematic (PPK) survey performed during the "ThyGraF - Tyrrbenian Gravity Flow" oceanographic campaign in the southern Tyrrhenian Sea conducted on board of the Urania $\mathrm{R} / \mathrm{V}$ (Research Vessel) are reported. The aim was to make an initial comparison between the altitudes acquired by the GNSS device and corrected with a geoid model and those recorded simultaneously by the tide gauges present in the area.

In the paragraph "materials and methods" the instruments used and the measurements carried out will be illustrated, in the paragraph "GNSS data processing" the processing carried out and the different strategies used will be reported and finally, in the paragraph "results and discussion" the results obtained will be compared with the tidal data and the conclusions will be illustrated.

\section{MATERIALS AND METHODS}

During the ThyGraF oceanographic survey conducted on board of the Urania R/V from $12^{\text {th }}$ to $19^{\text {th }}$ of February 2013, the geodetic team of the scientific crew was engaged in experimenting and validating some innovative techniques of satellite survey in navigation. For this purpose, the geodetic class GPS-GNSS receiver Topcon Legacy-E was used and the antenna (Topcon PGA) was installed on the top of the ship itself, thanks to the collaboration of the ship's personnel (In Figure 1 square antenna to the right of the main mast).

Before departure, a survey was carried out using a total station with the aim to measure the antenna height respect to the waterline. The result was $18.132 \mathrm{~m}$ with respect to the bottom of antenna mount.

The installation height was necessary to avoid cycle slip and electromagnetic disturbances from the ship's machinery, but it certainly amplified the variability of the three-dimensional coordinates recorded due to the continuous and physiological variation of the ship's attitude. So, the antenna was installed on one of the highest points of the ship where the only obstruction was the highest part of the mast. The antenna was in basic configuration without multipath limiting devices because these could have increased the effect of the wind, so for this first experiment it was decided not to use them. No extensive analysis of antenna effects was carried out in this first experiment.
The data surveyed (acquired in double frequency with sampling interval of one second) have subsequently been postprocessed with respect to the permanent stations of the new national dynamic network, these reference measurements have been made available by various agencies (University of Palermo, Calabria Region etc.). The survey and the subsequent postprocessing allowed to evaluate the three-dimensional position of the antenna itself, statically fixed to the body of the ship throughout the oceanographic survey, with centimetre accuracy. It is important to underline that the antenna was obviously affected by all the displacements and attitude variations (heave, roll, pitch and yaw) that affected the ship during its navigation. This series of measurements allowed us to evaluate their variations with great accuracy.

The GNSS survey allowed the altimetric comparison between the data provided by the tidal networks (referred to a conventional local zero with respect to a local tide gauge) and the ones observed in navigation (ellipsoidal heigh that must be corrected with geoid model ITALGEO05). This analysis highlights a fundamental aspect linked to the compatibility between different altimetric reference systems, in order to allow a connection between on-shore and off-shore heights.

\section{GNSS DATA PROCESSING}

The GNSS receiver positioned on the Urania R/V (Figure 1) acquired dual frequency data with $1 \mathrm{~s}$ sampling interval from $14^{\text {th }}$ to $18^{\text {th }}$ of February 2013; during the research survey the marine weather conditions were optimal.

The permanent station of Tropea (Table 1) belonging to the permanent network of Calabria region [18] was selected for data post-processing, hourly RINEX files with a sampling interval of $1 \mathrm{~s}$ were downloaded.

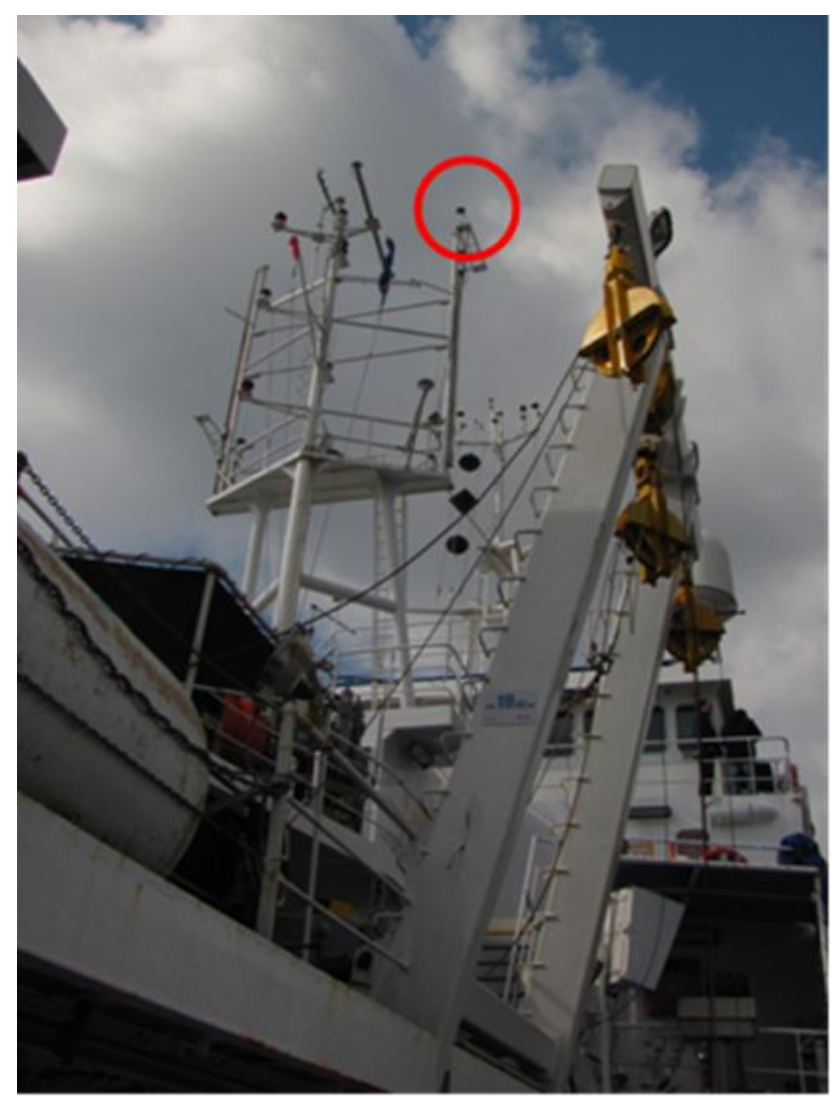

Figure 1. GNSS antenna and its installation on the Urania ship. 
Table 1. Coordinates and characteristics of the TROP station as reported on the operator's website (reference system WGS84-ETRS89; EPSG: 4937 [19]).

\begin{tabular}{ll}
\hline Name station & TROP \\
\hline Latitude & $38^{\circ} 40^{\prime} 45.6525^{\prime \prime} \mathrm{N}$ \\
Longitude & $15^{\circ} 53^{\prime} 48.2067^{\prime \prime} \mathrm{E}$ \\
$h$ in $\mathrm{m}$ & 100.086 \\
Antenna type & LEIAT504GG LEIS \\
Receiver & LEICA GRX1200GGPRO \\
\hline
\end{tabular}

\subsection{RTKlib}

The first step of the data processing was performed with RTKlib ver. 2.4.2, open-source package for GNSS positioning developed by Tomoji Takasu in 2007 [20], [21]. RTKlib can process data from different satellite systems (GPS, GLONASS, Galileo, QZSS and BeiDou) considering approaches both in realtime and post-processing and various position modes: Single, DGPS/DGNSS, Kinematic, Static, Moving-Baseline, Fixed, PPP-Kinematic, PPP-Static and PPP-Fixed.

Unfortunately, RTKlib provides a graphical interface where it is possible to upload only two RINEX files: one for the rover and a second for the base station; furthermore, the software does not manage the raw format of the Topcon receiver (Figure 2). Then, to facilitate the processing operations the data were managed with the open-source package TEQC by UNAVCO [22].

TEQC is a toolkit with three main functions: Translation, Editing, and Quality Checking, from which it gets its name. For our purposes, the two functions of translation and editing were exploited: the first function allows to convert (translate) GNSS raw receiver files into RINEX format (observation and navigational files); the second one allows to cut or splice RINEX files.

The data, in TPS format, acquired by the receiver positioned on the Urania $\mathrm{R} / \mathrm{V}$ were then converted to RINEX and reorganised into daily files with the TEQC software. In addition, the data from the TROP permanent station, already in RINEX format, were edited with TEQC to create a single daily file.

The output files from the TEQC software were imported into RTKlib, together with the precise ephemerides released by Crustal Dynamics Data Information System (CDDIS) [4] and processed in kinematic mode.

For the DOY046 (acquisition period from 15/02/13 00:00:00 to 15/02/13 23:59:59) and DOY047 (acquisition period from

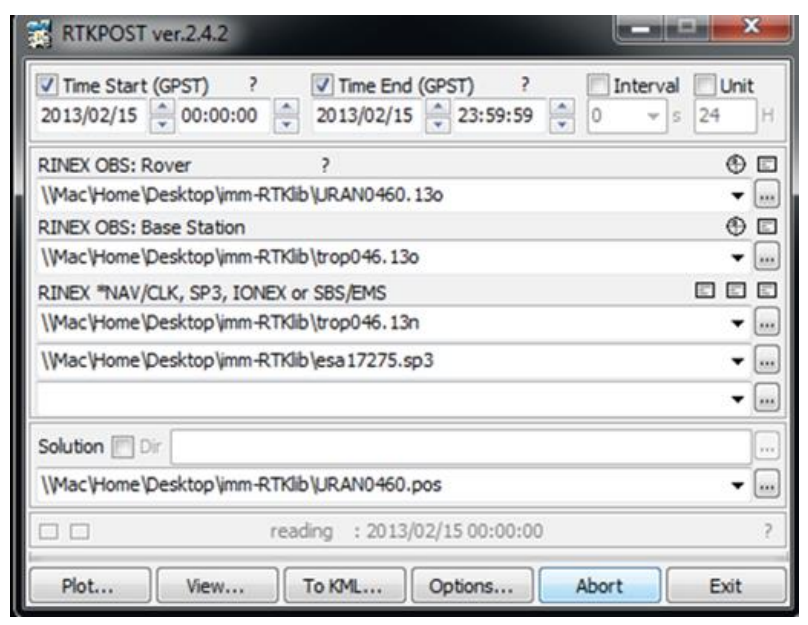

Figure 2. RTKlib options for the PPK data processing.
Table 2. Position estimated and their solutions.

\begin{tabular}{ccc}
\hline Position estimated & DOY046 & DOY047 \\
\hline Total & 85563 & 85233 \\
Fixed solution & $47573(56 \%)$ & $39609(46 \%)$ \\
Float solution & $37990(56 \%)$ & $43212(51 \%)$ \\
Single solution & 0 & $2412(3 \%)$ \\
\hline
\end{tabular}

Table 3. Position estimated and their solutions.

\begin{tabular}{c|ccc|ccc}
\hline & \multicolumn{3}{|c|}{ DOY046 } & \multicolumn{3}{c}{ DOY047 } \\
& Sdn $(\mathrm{m})$ & Sde $(\mathrm{m})$ & Sdu $(\mathrm{m})$ & Sdn $(\mathrm{m})$ & Sde $(\mathrm{m})$ & Sdu $(\mathrm{m})$ \\
\hline avg & 0.006 & 0.005 & 0.012 & 0.005 & 0.005 & 0.012 \\
$\max$ & 0.543 & 0.407 & 0.988 & 0.637 & 0.486 & 1.065 \\
$\min$ & 0.003 & 0.003 & 0.008 & 0.003 & 0.002 & 0.008 \\
\hline
\end{tabular}

$16 / 02 / 1300: 00: 00$ to $16 / 02 / 13$ 23:59:59), the number of fixed/float solution (Table 2) and the estimated standard deviations (Table 3) were reported.

Unfortunately, the TROP permanent station acquisitions for the period 19:00:00 - 19:59:59 was not available, then RTKlib software could only process the solution in single position (Table 2). As a consequence, the coordinates related to these 2412 observations were not considered in the results (Table 3) and in all figures related to DOY047 because of very low and not reliable solution precision.

The positions measured in kinematic mode, obtained processing the GNSS data acquired during the two days of navigation, show a similar level of precision with a mean value of $0.005 \mathrm{~m}$ for the planimetric coordinates and $0.012 \mathrm{~m}$ for heights.

The planimetric navigation paths of the ship is represented in GIS software (QGIS): on the first day (DOY046) the path was mainly a round trip between the two islands of Stromboli and Lipari and therefore away from the mainland. On the second day (DOY047) navigation started with a long "transfer" section from the islands to the mainland in a north-west -> south-east direction and then navigation along the coast and some grids in specific areas. In Figure 3 the navigation paths DOY046 (red track) and DOY047 (yellow track) and the permanent GNSS station TROP location (red triangle) are represented.

The daily trend of heights, despite high variability due to the vessel attitude, shows a periodic variation almost certainly due to the tidal effect (Figure 4a). During the second day (Figure 4b), a discontinuity is observed in the central hours of the day, probably

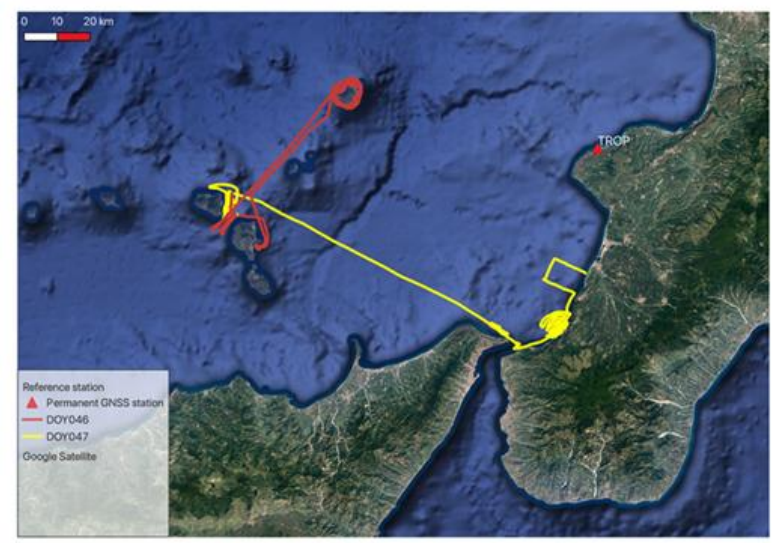

Figure 3. Navigation paths on DOY046 (red track) and DOY047 (yellow track) and the permanent GNSS station TROP location (red triangle). 
this trend is due to the well-known effects of local tidal disturbance observed in the Messina Strait.

\subsection{Topcon Tools}

The results of the heights measured in kinematic mode obtained from the processing of GNSS data in RTKlib was repeated for verification with a commercial software, Topcon Tools.

This verification was carried out because RTKlib sometimes has small "bugs" [21] and because, according to some authors, Topcon Tools would show very accurate results, in some cases even comparable with those of scientific software. This is probably due to a complete configurability of the processing [23]

The Topcon Tools package ver. 8.2.3 by Topcon Corporation was used for the kinematic measurements. The software allows the data processing from different devices such as total stations, digital levels and GNSS receivers, and it was used in several technical-scientific applications [24], [25]. Topcon Tools uses the Modified Hopfield Model for the tropospheric corrections [26]. The employed positioning mode was Code-based differential ("CODE DIFF"), the time range and the cut-off angle were set to 15 seconds and 10 degrees, respectively.

Recently Dardanelli et al. [27] showed that the hypothesis of a normal distribution is confirmed in most of the pairs and, specifically, the Static vs. NRTK pair seems to achieve the best congruence, while involving the PPP approach, pairs obtained with CSRS software achieve better congruence than those involving RTKLIB software. Although the lowest congruencies seem characterizing the pairs involving RTKLIB, this result should not be considered a criticism on the performance of this well-known open access program, which undoubtedly is one

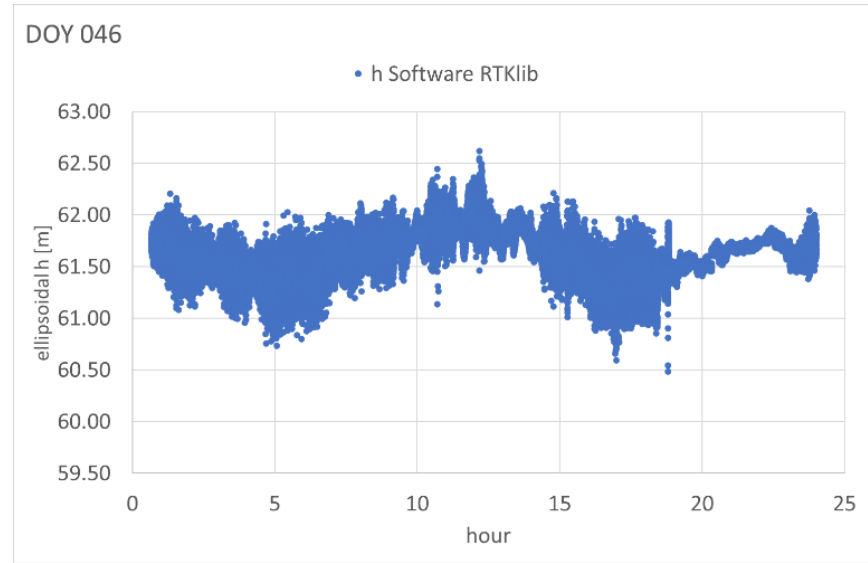

a)

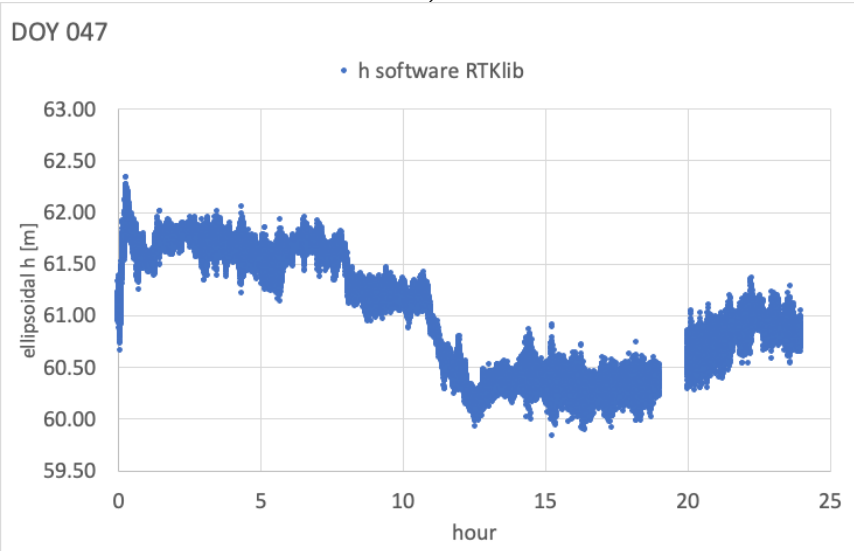

b)

Figure 4. Ellipsoidal heigh variations during DOY046 (a in figure) and during DOY047 ( $b$ in figure)
Table 4. Positions estimated with both packages and their estimated standard deviations.

\begin{tabular}{c|ccc|ccc}
\hline & \multicolumn{3}{|c|}{ DOY046 } & \multicolumn{3}{c}{ DOY047 } \\
& Sdn (m) & Sde $(\mathrm{m})$ & Sdu $(\mathrm{m})$ & Sdn $(\mathrm{m})$ & Sde $(\mathrm{m})$ & Sdu $(\mathrm{m})$ \\
\hline avg & 0.101 & 0.062 & 0.118 & 0.078 & 0.078 & 0.051 \\
$\max$ & 0.140 & 0.106 & 0.150 & 0.283 & 0.283 & 0.112 \\
$\min$ & 0.070 & 0.032 & 0.100 & 0.042 & 0.042 & 0.013 \\
\hline & & DOY046 & & & DOY047 & \\
& Sdn (m) & Sde $(\mathrm{m})$ & Sdu (m) & Sdn (m) & Sde (m) & Sdu (m) \\
\hline avg & 0.006 & 0.005 & 0.012 & 0.005 & 0.005 & 0.012 \\
$\max$ & 0.543 & 0.407 & 0.988 & 0.637 & 0.486 & 1.065 \\
$\min$ & 0.003 & 0.003 & 0.008 & 0.003 & 0.002 & 0.008 \\
\hline
\end{tabular}

among of the most useful GNSS processing software available, given its very straightforward applicability, considering also that our analysis is limited to few hours of data.

The results obtained from the Topcon Tools processing are different from those obtained with RTKlib, but the general trend that seems to mainly reproduce the tidal effects is very similar (Figure $5 \mathrm{a}$ and $\mathrm{b}$ ) as well as the numerical results (Table 4).

\section{RESULTS AND DISCUSSION}

The ellipsoidal heights processed with RTKlib and Topcon Tools were then compared with the hydrometric levels of some

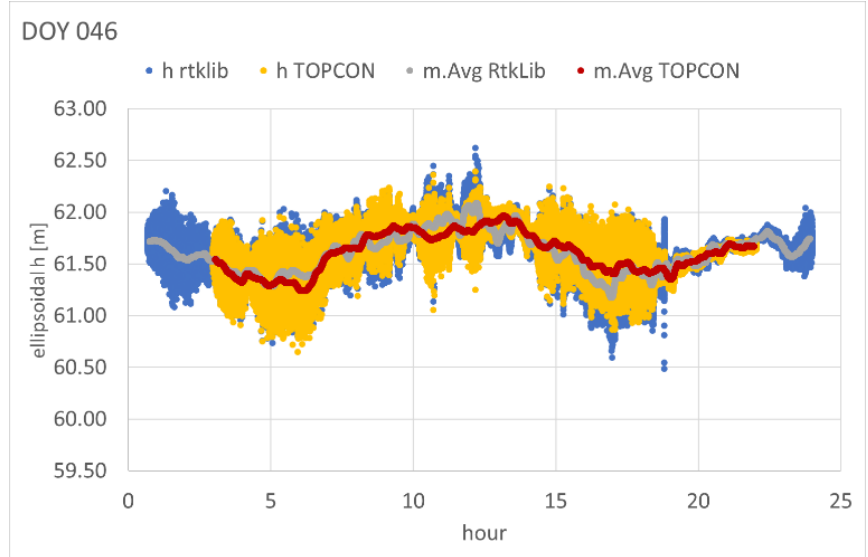

a)

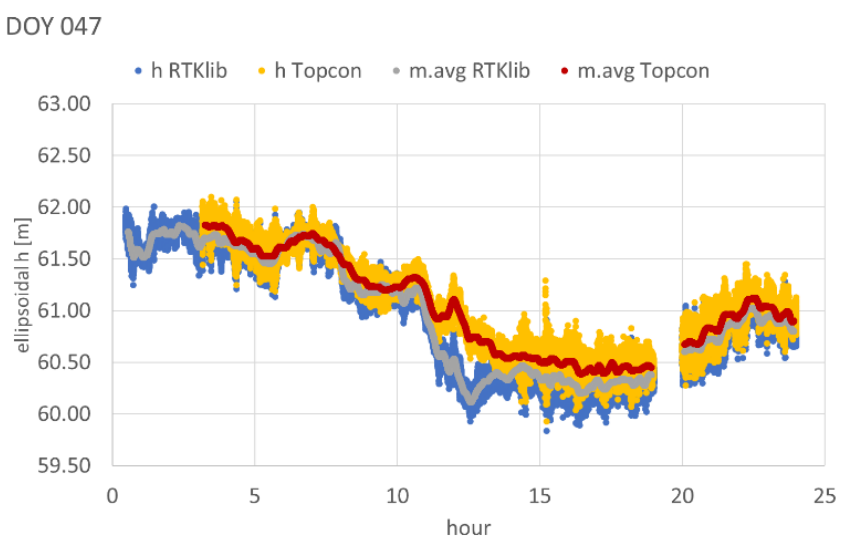

b)

Figure 5. Ellipsoidal height variations during DOY046 (a in figure) and during DOY047 (b in figure), comparison between RTKlib (blue dots) and Topcon Tools (orange dots) results. In red is the 10-minute moving average from Topcon Tools and in grey that of RTKlib. 


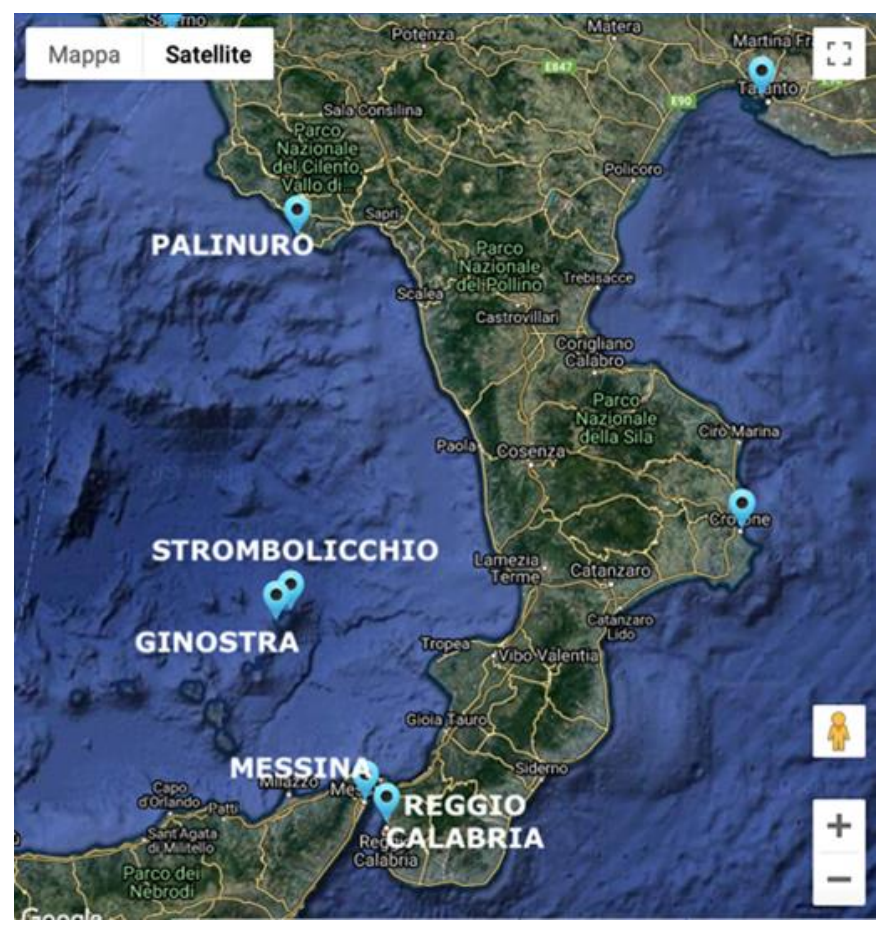

Figure 6. Tidegauge stations available in the study area.

stations belonging to the RMN - National Tidegauge Network [28].

RMN stations close to the study area are: "Ginostra", "Strombolicchio", "Reggio Calabria" and "Messina" (Figure 6).Unfortunately, the data from Strombolicchio station are not available for the period under examination.

We decided to compare the hydrometric level with the ellipsoidal height, only on the tide gauge station of Ginostra and Palinuro, while Reggio Calabria and Messina were not selected because they showed a very different trend probably due to the well-known local effects near the Messina Strait (Figure 7).

At first, the variations measured by the tide gauges were compared only in terms of trend with the heights measured by the GNSS receiver on board the ship. In order to filter the heights and limit the effect of the oscillations caused by navigation, a moving average over ten-minute periods was adopted (in the figure is the grey trend).

As already observed, there is an apparent similar trend between the tide gauge and the averaged GNSS altitudes but also a constant shift between them.

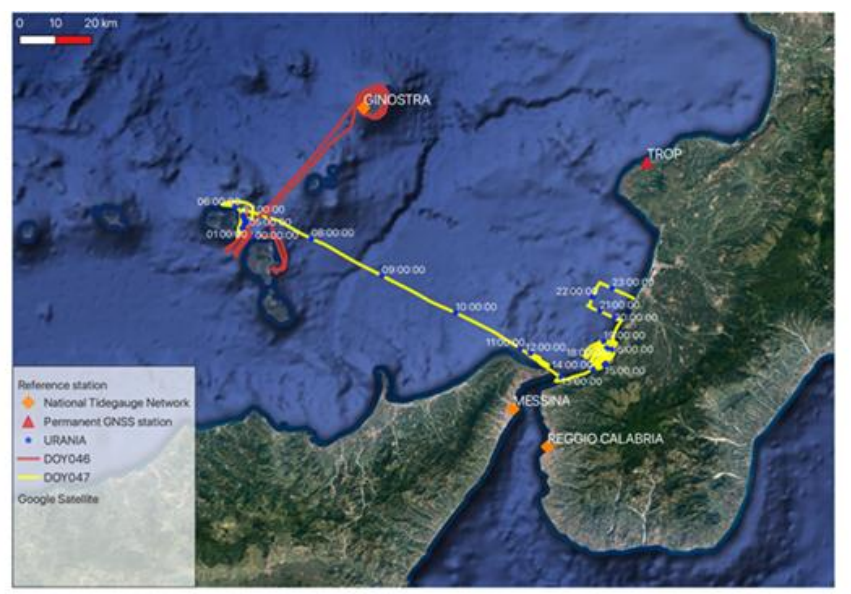

Figure 7. Tide gauges and path of the navigation during DOY046 and DOY047.

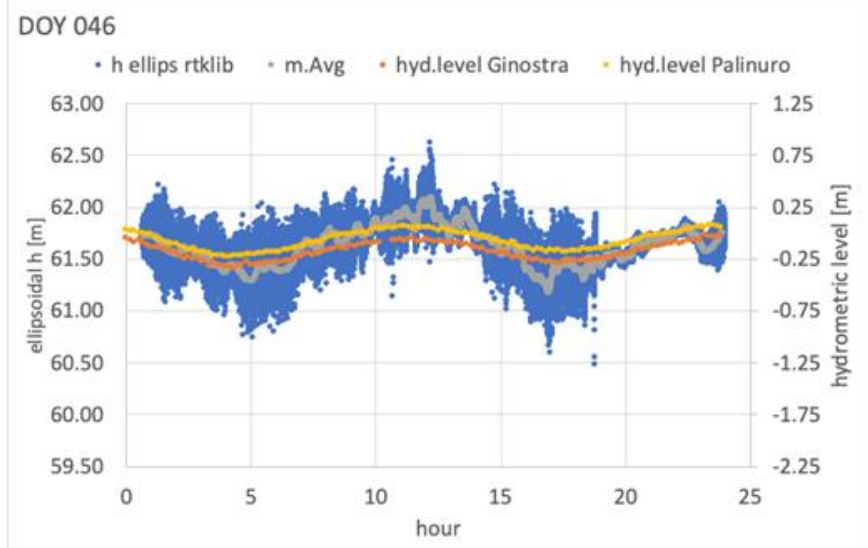

a)

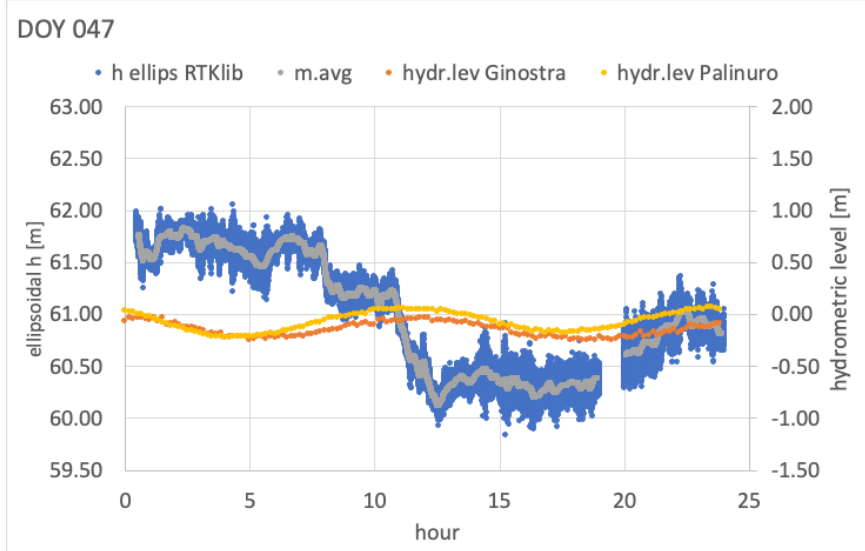

b)

Figure 8. Tide gauges trend and mean heights from GNSS receiver for DOY046 (a) and DOY047 (b), note the different origin of height of the two series.

For DOY046 the trend agreement continues very well for the whole day while for DOY047 there seems to be a noticeable discontinuity at a certain point. The causes may be various but probably the aforementioned tidal effects near the strait are the main cause (Figure 8).

For the reasons outlined above, it was decided to continue the analysis only on DOY046, which seems more significant.

It is important to remember that the orthometric correction operated with a geoid model brings the elevations to an equipotential surface of the gravitational field at a given point on the national territory (for Italy, Genoa) that in general does not

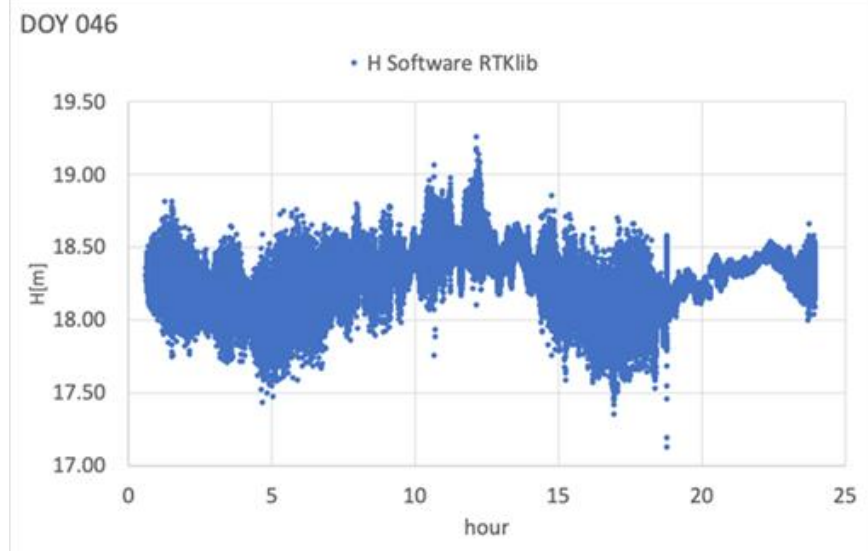

Figure 9. Orthometric heights for DOY046 (a) converted using ITALGEO2005 geoid model. 
coincide with the sea level in another position of the national territory at a given time [29], [30]. Moreover, there is a problem of connection of the various tide gauges to the national altimetric system and conventionally the "zero" of the tide gauge has no connection with the "zero" of the national altimetric system.

The ellipsoidal elevations measured with the GNSS receiver were converted into orthometric elevations ( $\mathrm{H}$ in Figure 9) with respect to the national altimetric system using the Geoid model ITALGEO2005, which is accredited with $2.5 \mathrm{~cm}$ of accuracy [5]. However, it should be noted that the reported accuracy is estimated on land where geoid-ellipsoid separation values measured on altimetric benchmarks are used to improve the estimate of geoid-ellipsoid separation itself. In our case some of the survey points are close to the coast and therefore the estimate of the geoid-ellipsoid separation should be reliable, while for offshore points the estimate is certainly less reliable. Moreover, the connection between the national and islands elevation systems cannot be made by precision geometric levelling but it is often made by trigonometric or GNSS levelling corrected later with the same geoid models.

The elevations were then converted from ellipsoidal to orthometric using the software "Geotrasformer" [31] that applies the resampling algorithms of the gridded geoid-ellipsoid separation values provided by the Italian Military Geographic Institute (IGMI), the official national geodetic agency that released the grids of the ITALGEO2005 model.

To compare surveyed data with the tide gauges information it is necessary subtract estimated antenna elevation (section 2) from the orthometric values themselves (GNSS measurements corrected with ITALGEO2005); it must be considered, however, that during navigation the ship can progressively but significantly change its height due to the discharge of waste water and fuel consumption, such variations can reach several centimetres during a campaign and their variation may not be constant, therefore an average value during the day can still give reliable information. It was decided to take an average of the orthometric heights for the entire day to reduce the effect of the tide, obtaining an average height of $18.276 \mathrm{~m}$. (including the height of the PGA2 antenna).

Considering the approximations mentioned above, a comparison was made between the heights obtained with GNSS measurements corrected with ITALGEO2005 and antenna elevation $(\widetilde{H}$ in Figure 10) and the heights reported at the same time by the two tide gauges considered significant: "Ginostra" and "Palinuro" (hydrostatic level in Figure 10).

The main trend of all three tracks (Figure 10) follows the same tidal repetitions. The gap in height between ship and tidal gauge data is due to the different definition of reference altimetric system, but the tidal effect is still predominant.

There is also a systematic shift between the heights of the two tide gauges, which may be due to local reasons of a different average sea level or, more likely, to a different materialisation during the installation of the tide gauge itself, but also to an imperfect connection between the tide gauges due to the difficulty of connecting the heights of an island (Ginostra) to the national altimetric system on the mainland.

\section{CONCLUSIONS AND FURTHER DEVELOPMENTS}

Considering the fluctuations due to the physiological continuous variation of the ship's attitude, the GNSS plot faithfully followed the trend of the tidal variations and highlighted the shifts between the GNSS data and the tide gauges

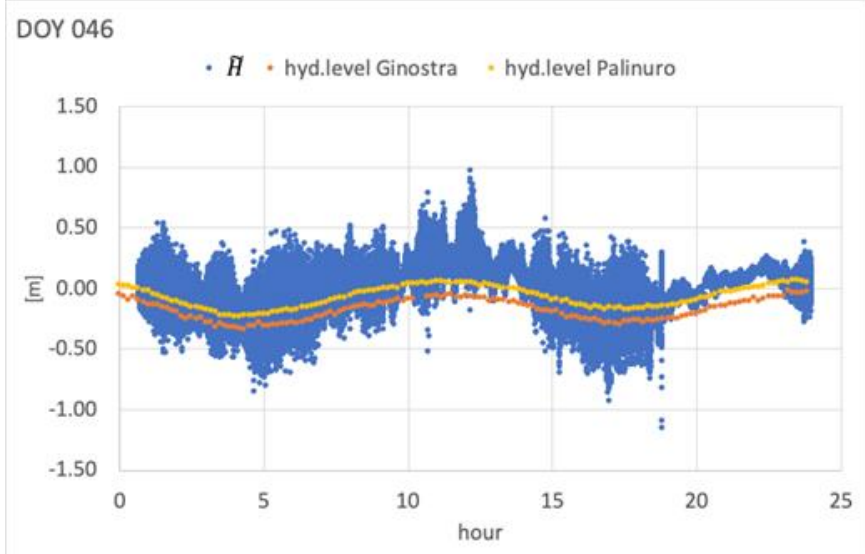

Figure 10. Orthometric heights for DOY046 (a) comparison with the heights reported at the same time by the two tide gauges considered significant: "Ginostra" and "Palinuro".

due to the different materialisation of the relative reference systems. In fact, even if the installation height amplified the variability due to the continuous variation of the ship's attitude, the average trend of the GNSS plot showed a relative trend very similar to that of the neighbouring tide gauges considered significant. After the orthometric correction of the heights and the estimation of the antenna height, it was possible to compare the data also "in absolute" (without forgetting the different altimetric references) and this comparison showed a remarkable agreement between the heights measured by the GNSS and the tide gauges, highlighting, at the same time, the effects of the different altimetric references. This experimentation highlighted the need to rethink or update marine altimeter datums especially in view of the possible imminent diffusion of low-cost differential GNSS receivers in navigation.

To study the possibility of highlighting any anomalies in operation, usually due to momentary dysfunctions of the satellite segment, the experimentation of the innovative approach "Multiconstellation" will be tested. This approach, designed by the same research group, can facilitate the detection of these anomalies while highlighting the corrections to be made. If this is verified, it would be possible to make the positioning measurements made during navigation more "robust" (i.e. less prone to errors), significantly improving their reliability. This could also be verified by a comparison with the information provided by the ship's DGPS-INS navigation system.

\section{ACKNOWLEDGEMENT}

This research was funded by the National Research Council (CNR) and carried out in the framework of the flagship project RITMARE (Ricerca ITaliana per il MARE). The authors would like to special thank the technical and scientific crews of the ThyGraF mission for their support in the installation of the receiver and for their continuous support in carrying out the measurement operations and its recordings.

\section{REFERENCES}

[1] E. Alcaras, C. Parente, A. Vallario,. The importance of the coordinate transformation process in using heterogeneous data in coastal and marine geographic information system, Journal of Marine Science and Engineering. 8(9) (2020) 708. DOI: $10.3390 /$ jmse8090708

[2] A. Mori, La cartografia ufficiale in Italia e l'Istituto Geografico Militare Nel cinquantenario Dell'istituto Geografico Militare 
(1872-1922); Istituto Geografico Militare, Stabilimento Poligrafico per l'Amministrazione della Guerra: Roma, Italy, 1922, 425 pp.

[3] L. Surace, I sistemi di riferimento geotopocatografici in Italia. Bollettino di Geodesia e Scienze Affini 57(1996) pp. 181-234, in Italian.

[4] R. Barzaghi, D. Carrion, M. Reguzzoni, G. A. Venuti, Feasibility study on the unification of the italian height systems using GNSS leveling data and global satellite gravity models, International Association of Geodesy Symposia (2016) pp. 281-288.

[5] R. Barzaghi, C. I. De Gaetani, B. Betti, The worldwide physical height datum project, Rendiconti Lincei, 31 (2020) pp. 27-34.

[6] G. Fastellini, F. Radicioni , A. Stoppini, R. Barzaghi, D. Carrion , New active and passive networks for a support to geodetic activities in Umbria, Bollettino di Geodesia e Scienze Affini, 67(3) (2008) pp. 203-227.

[7] L. E. Sjöberg, M. Bagherbandi, Quasigeoid-to-geoid determination by EGM08, Earth Science Informatics. 5(2) (2012) pp. 87 91.

[8] G. Inghilleri, Topografia Generale, ed. UTET, Torino, Italy (1974) 1019 pp.

[9] Intergovernmental Oceanographic Commission (IOC), Manual on Sea-level Measurements and Interpretation, Volume IV: An update to 2006. Paris, Intergovernmental Oceanographic Commission of UNESCO. (2006) 78 pp. (IOC Manuals and Guides No.14, vol. IV; JCOMM Technical Report No.31; WMO/TD. No. 1339).

[10] D. Casalbore, A. Bosman, D. Casas, E. Martorelli, D. Ridente, Morphological variability of submarine mass movements in the tectonically-Controlled calabro-Tyrrhenian continental margin (Southern Italy), Geosciences (Switzerland) 9(1) (2019) 43 DOI: $10.3390 /$ geosciences 9010043

[11] E. Petritoli, F. Leccese, High accuracy attitude and navigation system for an autonomous underwater vehicle (AUV). Acta Imeko 7 (2018) 2, pp. 3-9. DOI: $10.21014 /$ acta imeko.v7i2.535

[12] E. Martorelli, F. Italiano, M. Ingrassia, L. Macelloni, A. Bosman, A. M. Conte, S. E. Beaubien, S. Graziani, A. Sposato, F. L. Chiocci, Evidence of a shallow water submarine hydrothermal field off Zannone Island from morphological and geochemical characterization: Implications for Tyrrhenian Sea Quaternary volcanism, Journal of Geophysical Research: Solid Earth 121(12) (2016) pp. 8396-8414. DOI: $10.1002 / 2016 J B 013103$

[13] Istituto Mareografico nazionale. Online [Accessed 19 May 2021] https:/ /www.mareografico.it/?session $=0$ S26747870448387K707 58188D\&syslng $=i$ ita\&sysmen $=-1$ \&sysind $=-1$ \& syssub $=-$ $1 \&$ sysfnt $=0 \& \operatorname{code}=\mathrm{HOME}$

[14] S. Zollini, M. Alicandro, M. Cuevas-González, V. Baiocchi, D Dominici, P. M. Buscema, Shoreline extraction based on an active connection matrix (ACM) image enhancement strategy, Journal of Marine Science and Engineering 8(1) (2020) 9. DOI: $10.3390 /$ imse 8010009

[15] E. Alcaras, C. Parente, A. Vallario, Comparison of different interpolation methods for DEM production, International Journal of Advanced Trends in Computer Science and Engineering 8(4) (2019) pp. 1654-1659.

DOI: $10.30534 /$ ijatcse/2019/91842019

[16] D. Costantino, M. Pepe, G. Dardanelli, V. Baiocchi, Using optical satellite and aerial imagery for automatic coastline mapping, Geographia Technica 15(2) (2020) pp. 171-190.

DOI: $10.21163 /$ GT 2020.152 .17

[17] U. Robustelli, V. Baiocchi, L. Marconi, F. Radicioni, G. Pugliano, Precise point positioning with single and dual-frequency multi-
GNSS android smartphones, CEUR Workshop Proceedings, 2020, 2626

[18] Regione Calabria. Online [Accessed 19 February 2021] www.regione.calabria.it

[19] IGMI, Nota per il corretto utilizzo dei sistemi geodetici di riferimento allinterno dei software GIS aggionata a febbraio 2019. Online. [Accessed 22 November 2021]

https://www.sitr.regione.sicilia.it/wpcontent/uploads/nuova nota EPSG.pdf

[20] T. Takasu, RTKLIB: Open Source Program Package for RTKGPS, FOSS4G 2009 Tokyo, Japan, November 2, 2009

[21] P. Dabove, M. Piras, K. N. Jonah, Statistical comparison of PPP solution obtained by online post-processing services. IEEE/ION Position, Location and Navigation Symposium (PLANS), (2016) pp. 137-143. DOI: $10.1109 /$ PLANS.2016.7479693

[22] UNAVCO. Online [Accessed 19 May 2021] https://www.unavco.org/software/dataprocessing/teqc/teqc.html

[23] Topcon, Topcon Tools 7.3 Manual. Online [Accessed 19 May 2021]

https://www.topptopo.dk/files/manual/7010 0612 REVL To pconTools7 3 RM.pdf

[24] K. Dawidowicz,G. Krzan, K. Świątek, Relative Gps/Glonass Coordinates Determination in Urban Areas-Accuracy Anaysis.; In Proceedings of the15th International Multidisciplinary Scientific GeoConference SGEM 2015, Albena, Bulgaria, 18-24 June 2015 Volume 2 (2015) pp. 423-430. DOI: $10.5593 /$ SGEM2015/B22/S9.053

[25] M. Uradziński, M. Bakuła, Assessment of Static Positioning Accuracy Using Low-Cost Smartphone GPS Devices for Geodetic Survey Points' Determination and Monitoring. Appl. Sci. 10 (2020) 1-22. DOI: $10.3390 /$ app10155308

[26] C. Goad, L. Godman, A Modified Hopfield Tropospheric Refraction Correction Model. In Proceedings of the Fall Annual Meeting American Geophysical Union; San Francisco, CA, USA, 12-17 December 1974.

[27] G. Dardanelli, A. Maltese, C. Pipitone, A. Pisciotta, M. Lo Brutto, NRTK, PPP or Static, That Is the Question. Testing Different Positioning Solutions for GNSS Survey. Remote Sens. 13 (2021) 1406. DOI: $10.3390 / \mathrm{rs} 13071406$

[28] Istituto maregografico nazionale, Rete mareografica nazionale. Online. [Accessed 19 February 2021] https://www. mareografico.it/?session $=0$ S1758247488UC8488W UB85\&syslng $=$ ita\&sysmen $=-1$ \& sysind $=-1$ \&syssub $=$ $1 \&$ sysfnt $=0 \&$ code $=$ LIVE

[29] M. Pierozzi, Il sistema altimetrico italiano, la livellazione, lo zero idrografico ed $\mathrm{i}$ riflessi in ambito portuale, in Italian. Online. [Accessed 19 May 2021] http://www.assoporti.it/sites/www.assoporti.it/files/eventiEste rni/Pierozzi.pdf

[30] R. Barzaghi, A. Borghi, D. Carrion, G. Sona, Refining the estimate of the Italian quasigeoid, Bollettino di Geodesia e Scienze Affini 3 (2007) pp. 145-160.

[31] V. Baiocchi, P. Camuccio, M. Zagari, A. Ceglia, S. Del Gobbo, F. Purri, L. Cipollini, F. Vatore, Development of a geographic database of a district area in open source environment, Geoingegneria Ambientale e Mineraria 151 (2017) 97-101. 